PKS

PUBLIC

KNOWLEDGE

PROJECT

\section{REVISTA ENSINO DE GEOGRAFIA OJS \\ (RECIFE) \\ http://www.revista.ufpe.br/ensinodegeografia}

\title{
OS CARTOCAST'S COMO FERRAMENTA PARA O APRENDIZADO CARTOGRÁFICO E O DESENVOLVIMENTO DA DIDÁTICA
}

\author{
Tuane Telles Rodrigues \\ Universidade Federal de Santa Maria (UFSM) \\ Mestranda do Programa de pós-graduação em Geografia (PPGGeo) \\ tuanytel@hotmail.com \\ Roberto Cassol \\ Universidade Federal de Santa Maria (UFSM) \\ Prof. Dr. do Departamento de Geociências
}

\begin{abstract}
RESUMO: Novas tecnologias educacionais têm surgido como estratégias para o aprendizado eficiente e promovendo a conciliação simultânea entre teorias e práticas. Esta evolução no ensino traz benefícios tanto para os discentes quanto para os docentes que encontram nessas ferramentas a possibilidade de aperfeiçoamento profissional e desenvolvimento didático. É o caso da pesquisa que apresentamos neste artigo, realizada durante o estágio de docência orientada I, na disciplina de Geografia Ensino I, que tem como proposta auxiliar os futuros professores no desenvolvimento da didática e a percepção sobre como os alunos aprendem e compreendem os conteúdos da cartografia escolar. Ela teve como objetivo a criação de CartoCast's (podcasts cartográficos) como forma de desenvolver a organização, a narrativa e a criatividade na transmissão de conteúdos de cartografia sem o uso de imagens, fazendo dela uma ferramenta didático-pedagógica. O método utilizado consistiu em aulas teóricas; realização de um minicurso sobre o uso do software utilizado na produção; criação por parte dos integrantes da turma, apresentação e publicação em site para que ficasse disponível a todos. Os resultados foram verdadeiramente interessantes, pois houve desde produções bem construídas a superação da timidez por parte da turma, o que valida o recurso em relação aos objetivos propostos.
\end{abstract}

Palavras-chave: Cartografia; ferramenta; CartoCast's.

\section{THE CARTOCAST'S AS A TOOL TO THE CARTOGRAPHIC LEARNING AND THE DEVELOPMENT OF DIDÁDITCA.}

\begin{abstract}
The new educational technologies have emerged as a strategy for efficient learning, promoting the simultaneous reconciliation between theories and practices. This evolution in teaching brings benefits both for students and for teachers who find in these tools the possibility of professional improvement, such as didactic development. As is the case of the research presented in this article, conducted during the stage of oriented teaching I, in the discipline of Geography Teaching I, whose purpose is to assist future teachers in the development of didactics and the perception about how students learn and understand the
\end{abstract}


contents of school cartography. It aimed to create CartoCast's (cartographic podcasts) as a way to develop organization, narrative and creativity in transmitting cartographic contents without the use of images, making it a didactic-pedagogical tool. The method used consisted of theoretical classes; performing a mini-course on the use of software used in production; creation by the members of the class, presentation and publication on site so that it was available to all. The results were truly interesting, from very well-constructed productions to overcoming shyness by a large part of the class, validating the resources as a way to reach the proposed objectives.

Keywords: Cartography; tool; CartoCast's

\section{INTRODUÇÃO}

Estamos vivendo na era de grandes transformações no ensino, e para Geografia não é diferente, pois buscamos estudar novos métodos e ferramentas que facilitem o aprendizado dos alunos de maneira cada vez mais dinâmica, moderna e interativa, atendendo aos anseios das novas gerações atentas a essas mudanças. A linha temporal que divide a época em que os docentes foram discentes e hoje, quando os discentes tornaram-se docentes em atuação, está profundamente marcada pela evolução no ensino e na aprendizagem, pois quando comparamos os atuais métodos de ensino com aqueles considerados arcaicos, percebemos que a didática tinha na hierarquia um de seus principais valores. Felizmente as novas teorias que dão aos alunos o protagonismo em sala de aula motivaram em nós, docentes, um crescimento profissional verdadeiramente benéfico, algo que transformou as relações que temos dentro e fora do ambiente escolar.

Quando tratamos do tema do ensino de Geografia é inevitável não pensarmos nos mapas como a forma padrão de apresentação desta ciência. Graças à Cartografia Escolar podemos entender o modo como os alunos compreendem os conteúdos cartográficos e os valores sociais, ambientais, reflexivos e críticos que se manifestam, em múltiplas escalas, nas representações do espaço, envolvendo desde o estudo do lugar até a localização dos objetos vistos no céu.

Todavia, os alunos por vezes apresentam dificuldades de compreensão dos conteúdos relativos à Cartografia, muitas vezes por não conseguirem produzir relações com seus espaços de vivência, não estabelecendo assim a familiaridade entre o conteúdo e o mundo que os rodeia. Esta problemática é a principal preocupação dos educadores e objeto de grande discussão em âmbito escolar e acadêmico. Para sanar a dificuldade por meio de recursos didáticos apropriados acreditamos que é fundamental estabelecer o diálogo sobre a formação docente como um esforço de investimento sólido na promoção da capacidade de compreender os objetos representados com o auxílio da cartografia e seus conteúdos. 
A pesquisa foi desenvolvida durante o estágio de docência orientada I, no segundo semestre de 2017, na disciplina de Geografia e Ensino I do curso de Geografia Licenciatura Pleno da Universidade Federal de Santa Maria (UFSM). Esta disciplina é um seguimento de outra, oferecida no semestre anterior, chamada Cartografia I, e tem como eixo central auxiliar os futuros professores no desenvolvimento da didática e fomentar a percepção sobre como os alunos da educação básica aprendem e compreendem os conteúdos da Cartografia escolar, buscando de forma permanente a construção de propostas que facilitem a alfabetização e o letramento cartográfico no ensino fundamental, assim como sua retomada no ensino médio.

O objetivo desta pesquisa foi a de fomentar e discutir novas formas de ensino e de aperfeiçoamento técnico e didático docente por meio de ferramentas pouco utilizadas, como a criação dos CartoCast's ${ }^{1}$ (podcast's ${ }^{2}$ cartográficos), vistos como uma ferramenta didáticopedagógica capaz de desenvolver a organização, a narrativa e a criatividade na transmissão de conteúdos de Cartografia sem o uso de imagens..

\section{FUNDAMENTOS TEÓRICOS}

O conhecimento geográfico é desenvolvido de maneira gradual, com esforço, continuidade, e criatividade, características indispensáveis para o exercício docente nesta ciência, pois nos dias atuais é comum lidar com jovens e adultos atentos às novas tecnologias da informação e mais críticos quanto ao sistema de ensino, bem como a estrutura e o desenvolvimento da sociedade. Com a evolução desse pensamento que chega ao meio acadêmico e escolar, buscamos nos adaptar, evoluindo e construindo como educadores uma perspectiva do fazer autônomo, do compreender contextualizado e da aplicação teórica narrada de forma objetiva e essencialmente significativa aos alunos, por meio da prática docente que busca corresponder às expectativas tanto dos discentes em sala de aula quando do próprio educador em lecionar com qualidade, para satisfazer ao máximo a curiosidade e o entendimento da importância e influência da Geografia no cotidiano de todos nós. Para Moraes (1998, p.166), a formação do indivíduo crítico exige estimular o aluno a questionar fornecendo-lhe os elementos que fomentem a busca por respostas e a formação de novas perguntas, colaborando para a formação do cidadão democrático que invista no "respeito à diferença considerando a pluralidade de visões como um valor em sí”.

\footnotetext{
${ }^{1}$ Analogia criada a partir da intersecção das palavras Cartografia e Podcast's.

${ }^{2}$ Os Podcast's são uma ferramenta de comunicação amplamente utilizada atualmente, seja com a finalidade de divertimento ou como meio de comunicação para acesso a notícias.
} 
Esse pensamento pode ser aplicado em outras formas de ver o processo de ensino e aprendizagem em qualquer nível escolar, como é o caso dos alunos de graduação, futuros professores e o desenvolvimento reflexivo da sociedade e do embasamento crítico sobre a forma de ver e interpretar o espaço geográfico. Com isso é importante considerar as técnicas utilizadas com essa finalidade, buscando aquelas que promovam a evolução didática e profissional, em qualquer conteúdo próprio do conhecimento geográfico, como a cartografia e suas variadas possibilidades de representar o mundo, assim como suas complexas relações socais que geram efeitos aparentemente abstratos, mas que são passíveis de organização e concretização por meio da Cartografia. Segundo Straforini (2004), para que a educação tenha sentido na sociedade, é preciso possibilitar o seu entendimento no pretérito, pois é dessa forma que se constrói o sentido daquilo aprendido, de forma que o presente não descarte a história e não ignore o futuro.

Frente à estrutura da Geografia enquanto disciplina escolar, temos na Cartografia a base fundamental para compreender as dinâmicas do espaço geográfico, sendo de grande importância como instrumento de desenvolvimento cognitivo e socioespacial. Para isso é preciso empenho e dedicação para que o aprendizado seja proporcionado da melhor forma possível.

O conceito de Cartografia, estabelecido pela Associação Cartográfica Internacional (ACI), em 1966, e posteriormente confirmado pela UNESCO, define esse campo como "o conjunto de estudos e operações científicas, técnicas e artísticas que tendo por base os resultados de observações diretas ou da análise de documentação se volta para a elaboração de mapas, cartas e outras formas de expressão ou representação de objetos, elementos, fenômenos e ambientes físicos e socioeconômicos, bem como a sua utilização”. Com isso, a alfabetização cartográfica possibilita o acesso a conteúdos que fomentam o desenvolvimento do pensamento crítico e consciente. Os Parâmetros Curriculares Nacionais de Geografia (BRASIL, 1998, p. 33) afirmam que a Cartografia é um conhecimento que vem se desenvolvendo desde a préhistória até hoje, e que "esta linguagem possibilita sintetizar informações, expressar conhecimentos, estudar situações, entre outras coisas, sempre envolvendo a ideia de produção do espaço, sua organização e distribuição.”.

A dificuldade no aprendizado cartográfico, relatada por muitos estudiosos do tema, como Simielli (1986), é percebida durante o processo de compreensão da linguagem cartográfica e seus recursos. Esse problema é a principal preocupação dos educadores que tentam atenuar a dificuldade por meio de recursos didáticos apropriados, do uso de discursos 
mais simples e da proposta de um pensamento racional e reflexivo partindo do princípio de que a construção desse desenvolvimento torna necessário o esforço conjunto entre professores e pesquisadores no estudo da percepção cartográfica em todos os níveis de aprendizagem, do desenvolvimento da orientação e lateralidade, desde as crianças pequenas até a maturidade cognitiva de alunos dos cursos de graduação em Geografia.

A Cartografia é capaz de representar espaços de relevância geográfica, desde um lugar por meio das plantas, até um território por meio da abrangência de um mapa em pequena escala. Esse feito cartográfico revela aos alunos a versatilidade em representar por meio dessas variedades de escalas que a arte de conceber representações possui, mostrando que a superfície terrestre é constituída de muitos espaços geográficos. Para Callai (2013, p.140), o estudo da Cartografia pode ser feito mediante a visão de um lugar, com a finalidade de "perceber as bases concretas para encaminhar a compreensão das relações sociais, do acesso ao espaço para viver e das condições para tanto". Segundo Bento (2014, p.145), "não se ensina, mas se constrói, se realiza. A Cartografia tem um movimento próprio, relativamente independente, realizado pelos professores e demais sujeitos da prática escolar que tomam decisões sobre o que é ensinado efetivamente.” Essa conciliação prática da estrutura cartográfica é coerente do ponto de vista técnico, pois ela apresenta uma organização sistemática e fixa, variando em objetivos, no desenvolvimento artístico na escolha de figuras ou cores além das convencionais, e na abstração de elementos que podem oferecer excessos na contrução e na leitura da representação, o que é fundamental para a sólida interpretação da narrativa cartográfica.

De acordo com Castrogiovanni e Goulart (1998, p.130), "a Geografia, mais especialmente enquanto disciplina escolar, deve levar os alunos a entender o espaço", mostrando como as sociedades se transformaram apropriando-se dos elementos da natureza, assim como as técnicas que possibilitaram os grandes feitos históricos da transformação social humana. De forma semelhante, Vesentini (2004, p.228) diz que

[...] um ensino crítico da Geografia não se limita a uma renovação do conteúdo - com a incorporação de novos temas/problemas, normalmente ligados às lutas sociais: relações de gênero, ênfase na participação do cidadão/morador e não no planejamento, compreensão das desigualdades e das exclusões, dos direitos sociais (inclusive os do consumidor), da questão ambiental e das lutas ecológicas etc. Ela também implica em valorizar determinadas atitudes combate aos preconceitos; ênfase na ética, no respeito aos direitos alheios e às diferenças; sociabilidade e inteligência emocional - e habilidades (raciocínio, aplicação/elaboração de conceitos, capacidade de observação e de crítica etc.). 
Nesse contexto os domínios técnicos e naturais foram concebidos com bases geográficas. Straforini (2004) oferece um complemento significativo ao papel da Geografia nessa mesma perspectiva, dizendo que a Geografia assume uma função central na busca de outras possibilidades sobre a existência do homem, pois ela é capaz de fornecer, como a ciência das técnicas, o conhecimento das condições que implicam os processos evolutivos.

Todo aprendizado promovido pelos centros acadêmicos formadores de professores de Geografia tem como ponto inicial a linguagem cartográfica no âmbito escolar. Questionando o sistema até então vigente no ano de sua contribuição a ciência geográfica, Lacoste (1997, p. 55) diz que:

(...) Vai-se à escola para aprender a ler, a escrever e a contar. Por que não para aprender a ler uma carta? Por que não para compreender a diferença entre uma carta em grande escala e uma outra em pequena escala e se perceber que não há nisso apenas uma diferença de relação matemática com a realidade, mas que elas não mostram as mesmas coisas? Por que não aprender a esboçar o plano da aldeia ou do bairro? Por que não representam sobre o plano de sua cidade os diferentes bairros que conhecem, aquele onde vivem, aquele onde os pais das crianças trabalham etc. Por que não aprender a se orientar, a passear na floresta, na montanha, a escolher determinado itinerário para evitar uma rodovia que está congestionada?

A linguagem cartográfica ocorre principalmente de maneira gráfica. Ela exige de seu leitor o conhecimento sobre a formação de signos e símbolos aplicados aos mapas e outras formas de representação do espaço. Durante a aprendizagem cartográfica, temos como principais recursos pedagógicos as imagens, as tecnologias e o professor como construtor auxiliar desses conhecimentos complexos, pois ele adapta os conteúdos a uma linguagem acessível aos alunos. Para que isso aconteça é necessário que o profissional tenha bom domínio didático. A oralidade e o apoio teórico-metodológico desempenham aí papel importante.

\section{A IMPORTÂNCIA DA ORALIDADE NA DIDÁTICA}

Comunicar-se é parte fundamental de qualquer relação familiar ou social, pelo urso da oralidade ou da expressão por meio dos sinais utilizados pelas comunidades surdas, e n contexto escolar ela torna-se fundamental em sala de aula, tanto para os discentes em expressar suas opiniões ou saber como questionar algo que precisa ser trazidos às claras em algum conteúdo, quanto para os professores ao pedir atenção por paetê dos alunos, solucionar conflitos, indagar para estimular questionamentos ou explicar um conteúdo complexo. No caso da pesquisa aqui 
retratada, buscamos contribuir para o aperfeiçoamento desse ato fundamentalmente decisivo para o aprendizado de muitos alunos.

Por meio da oralidade a didática toma forma, é através dessa comunicação que outros objetos são introduzidos como ferramenta de exemplificação daquela teoria transmitida verbalmente. Mas o que é oralidade? Segundo Castilho (2000, p.89) o conceito de oralidade por meio da analise temporal e linguística dizendo que, "em toda a sua história, a Linguística sempre esteve atravessada pela ideia de que a língua falada é a manifestação primordial da linguagem e seu objeto primeiro de estudos." Contudo, apensar de bem-vindos, estes propósitos só puderam se transformar em ações depois de uma inovação tecnológica, como a invenção do gravador portátil que permitiu a investigação concreta da produção oral dos indivíduos.

Segundo os Parâmetros Curriculares de Língua Portuguesa (1998, p. 67-68)

Ensinar língua oral deve significar para a escola possibilitar acesso a usos da linguagem mais formalizados e convencionais, que exijam controle mais consciente e voluntário da enunciação, tendo em vista a importância que o domínio da palavra pública tem no exercício da cidadania. Ensinar língua oral não significa trabalhar a capacidade de falar em geral. Significa desenvolver o domínio dos gêneros que apoiam a aprendizagem escolar de Língua Portuguesa e de outras áreas (exposição, relatório de experiência, entrevista, debate etc.) e, também, os gêneros da vida pública no sentido mais amplo do termo (debate, teatro, palestra, entrevista etc.).

Para Marcuschi (2001, p.25) a oralidade seria uma prática social interativa com a finalidade de comunicar e apresentar "sob variadas formas ou gêneros textuais fundados na realidade sonora; ela vai desde uma realização mais informal à mais formal nos mais variados contextos de uso." Para ele, a fala é "uma forma de produção textual-discursiva para fins comunicativos na modalidade oral (situa-se na oralidade, portanto), sem a necessidade de uma tecnologia além do aparato disponível pelo próprio ser humano”. (ibid.). Marcuschi e Dionísio (2007, p. 29) afirmam que,

\begin{abstract}
A visão da oralidade nos manuais escolares é muito superficial e pouco explícita. Não raro é também equivocada e confunde a análise da oralidade com algumas atividades de oralização da escrita. Toma a escrita como um padrão linguístico no qual se define o que é certo e errado, sem atenção para a diversidade da produção textual.
\end{abstract}

Quando a prática docente, a transmissão de informações e a construção de conhecimentos teóricos, Libâneo (1994, p.225) afirma sabiamente que a ação docente ganha eficácia na medida em que o professor vai acumula o enriquecimento promovido pelas experiências ao lidar com situações concretas de ensino. "Isso significa que, para planejar, o 
professor se serve, de um lado, dos conhecimentos do processo didático e das metodologias específicas das matérias e, de outro, da sua própria experiência prática."

Segundo Dolz, et. al. (2004, p. 214), o diálogo sobre as capacidades fundamentais ao campo "linguístico (técnicas de retomada do discurso do outro, marcas de refutação etc.), cognitivo (capacidade crítica) e social (escuta e respeito pelo outro), como do ponto de vista individual (capacidade de se situar, de tomar posição, construção de identidade)". Com isso o estudo da prática didática promovidas pela oralidade tem efeito em outros arranjos que compõem os aspectos da inteligência e da interação com o meio social em que vivemos.

Segundo Freitas e Abreu (2016, p. 50), por diversas vezes durante o processo de formação ou ainda quando concluímos nossa graduação e atuando como professor "caímos na rotina de utilizarmos somente o livro didático ou o material pré-estabelecido como recurso para a ministração de nossas aulas, essa atitude pode ser justificada pela falta de vontade de se esforçar em busca de materiais extras ao que foi instituído", ou também pelo fato do professor não dispor de "materiais atualizados e didáticos para poder tornar a nossa aula, mais proveitosa e atrativa para os alunos bem como para o (a) professor (a) que ministra a aula." (ibid.). O mesmo dizem Richter e Bueno (2013, p.17), que tratam o trabalho com os mapas uma "prática baseada na leitura e na interpretação das representações cartográficas proporcionam um amparo seguro para o exercício da docência, além das novas estratégias de ensino que provocam a criatividade e inventividade" com isso os professores conseguem utilizar das experiências pessoais como ferramenta de apoio ao ensino e aprendizagem, proporcionando o estímulo para a participação dos alunos.

A oralidade e didática também estão presentes nas palavras de Schneuwly (2004, p.114) ao dizer que

Não existe uma essência mítica do oral que permitiria fundar sua didática, mas práticas de linguagem muito diferenciadas, que se dão, prioritariamente, pelo uso da palavra (falada), mas também por meio da escrita, e são essas práticas que podem se tornar objetos de um trabalho escolar.

Com isso é evidente a importância do aprimoramento linguístico na formação profissional com vistas a boa didática que permite a compreensão dos conteúdos diversos, como a cartografia, por parte do aluno, em seu complexo e sofisticado arranjo informativo apresentado por meio das imagens, mas suas bases conceituais e fundamentadas são passadas inicialmente por meio e da descrição de sua aplicabilidade. 


\section{APRENDER A ENSINAR CARTOGRAFIA}

Para muitos, a docência é vocação, uma aptidão que permite ao professor dispor de paciência, organização de pensamento e capacidade de adaptar linguagens dos conteúdos mais complexos, mas para outros, mesmo que tenham amor pela prática docente, percebemos dificuldades nos quesitos anteriormente mencionados. De todo modo, o desenvolvimento das habilidades utilizadas na prática docente precisa ser aprimorado por todos os professores. E é isso que as disciplinas de ensino presentes nos cursos de graduação para futuros professores têm como proposta fundamental.

O ensino de Geografia não é diferente. Ela possui diversas áreas de interesse social e natural que se articulam em um sistema de reflexões que fazem dela uma das ciências mais influentes e importantes no pensamento social. Com a Cartografia não poderia ser diferente, essa influente área de aprendizado geográfico é uma das mais discutidas atualmente, principalmente em relação a como obter sucesso em seu aprendizado e ensino, e tendo uma linguagem deveras refinada e complexa, é a área responsável por espacializar conhecimentos reais ou abstratos sobre uma representação.

Ensinar Cartografia com seus vastos conteúdos e formas de representações do espaço terrestre e cosmográfico ${ }^{3}$ não é uma tarefa fácil. Requer sensatez, criatividade, liberdade de pensamento e uma boa dose de criticidade. Para Passini (2012, p.29), "o conhecimento desse espaço é empírico, o espaço sensório-motor, perceptivo e intuitivo". Para ele, entender a Geografia do espaço de sua vida, deve tomá-lo como um objeto de estudo, desvendá-lo e sistematizá-lo.

Não é por menos que a concepção de mapas parte de um hábil procedimento reflexivo, técnico e artístico, pois criar representações do espaço é algo fundamentalmente eficiente no processo de aprendizado cartográfico e geográfico. Seus conteúdos podem ser perfeitamente discutidos sem a necessidade imediata de uma imagem de apoio, construindo, em um primeiro momento, a base teórica e conceitual de uma das etapas que providenciam a boa concepção do mapeamento desejado ou do ensino escolar.

Uma das formas mais comuns no processo de alfabetização cartográfica é o ensino dos elementos que compõem os mapas, além do próprio alfabeto cartográfico definido como ponto,

\footnotetext{
${ }^{3}$ Muitos conteúdos utilizados em Cosmografia Geográfica, Astronomia e Astrofísica fazem uso dos mesmos conteúdos cartográficos com a finalidade de localizar fenômenos no céu, bastando ter a Terra como ponto de referência em relação ao que se conhece por esfera celeste onde todos os objetos do universo estariam fixos.
} 
linha e polígono. Para isso, são utilizados os mapas que mostram como esses conteúdos têm suas aplicações práticas. Entretanto, boa parte do ensino é comunicação, é explicação, é diálogo, e para que isso aconteça o professor deve conseguir articular seus conhecimentos a uma boa forma de transmissão. Mesmo que seja para explicar o que está presente nos livros didáticos, ser um bom interlocutor é fundamental para ter êxito.

Assim como conversar sobre política, sobre o endereço de algum lugar ou simplesmente contar as fofocas da semana, no ensino a comunicação deve ser precisa, clara, objetiva, e por essa razão, transmitir informações da melhor forma requer prática constante. Por essa razão, os recursos de áudio podem ser uma boa estratégia para o desenvolvimento da oralidade, por proporcionarem ao locutor a possibilidade de se escutar, e assim corrigir vícios linguísticos, buscar novos termos e ainda superar "travas" narrativas ou descontextualização exemplificativa, comum quando se tenta desesperadamente dar sentido a algum conteúdo buscando relações com o cotidiano dos alunos ou com atividades corriqueiras na rotina dos alunos.

Bento (2014, p. 143) discute o processo de ensinar e aprender Geografia com vistas aos debates presentes na contemporaneidade, "fundamentando-se em orientações teóricas do campo acadêmico brasileiro para uma melhor compreensão desse processo de ensino e aprendizagem", buscando um entendimento da atuação docente em Geografia, e observando a importância dada às motivações dos alunos e à valorização do lugar enquanto uma mediação didática potencial à construção do conhecimento geográfico. Mas aprender a ensinar é outro processo que merece atenção na prática didática, em especial na docência em Geografia, seja escolar ou acadêmica, e para que isso ocorra de forma proveitosa à evolução e aperfeiçoamento profissional, é interessante o uso das tecnologias como ferramenta de construção da autopercepção enquanto professor na transmissão de conhecimentos. Assim como afirma Kenski (2010, p. 106):

[...] identificar quais as melhores maneiras de usar as tecnologias para abordar um determinado tema ou projeto específico ou refletir sobre eles, de maneira a aliar as especificidades do 'suporte' pedagógico (do qual não se exclui nem a clássica aula expositiva nem, muito menos, o livro) ao objetivo maior da qualidade de aprendizagem de seus alunos.

Aprender novos assuntos é uma etapa que requer empenho, mas assumir o papel de mediador entre os conteúdos e os alunos requer um esforço diferenciado, pois a transmissão de conhecimentos é uma das características que definem um bom professor, que não deve 
simplesmente despejar conteúdos de forma imprudente, mas sim construir percepções e facilitar a compreensão, o diálogo e o senso crítico. O professor autônomo é aquele capaz de prover questionamentos onde as respostas sejam alcançadas por meio do pensamento e do raciocínio independentemente dos materiais disponíveis em aula, como os livros didáticos que segundo Pontuschka, et. al. (2009, p. 339)

[...] continuam a ser o grande referencial na sala de aula para alunos e professores das escolas públicas e privadas do país, embora sejam utilizados de formas variadas: às vezes, permitindo que o aluno faça uma reflexão; muitas vezes, trabalhando de modo tradicional e não reflexivo.

Segundo Passini (2007, p. 148), “o ensino de Geografia e o de Cartografia são indissociáveis e complementares: a primeira é conteúdo e a segunda é forma. Não há possibilidade de se estudar o espaço sem representá-lo, assim como não podemos representar um espaço vazio de informação.” Concordamos com esta afirmação, no entanto, a prática de ensino requer outras características dos educandos, como uma maior independência e autonomia didática na construção do conhecimento em sala de aula, principalmente quando o professor não dispõe de tempo ou ferramentas de mapeamento para aplicar as teorias à prática. Com isso é importante aprender a ensinar Cartografia por meio de outras formas, como um discurso bem estruturado e alinhado aos conhecimentos que possibilitam as ações de representações do espaço.

\section{METODOLOGIA}

Os conteúdos que versam sobre o papel da Cartografia Escolar e a forma como a alfabetização cartográfica ocorre nas crianças de sexto ano do ensino fundamental, o apoio dos parâmetros curriculares nacionais, os principais teóricos sobre o desenvolvimento da linguagem e da inteligência (como Piaget) e as ferramentas de mapeamentos e os mapas utilizados nos livros didáticos construídos de forma acessível aos alunos estavam sendo discutidos com a turma desde o começo da disciplina. Essa base teórica e reflexiva possibilitou a ampliação de visões e propostas sobre métodos de ensino, ferramentas que facilitassem a aprendizagem dos alunos e de técnicas que aperfeiçoassem a prática docente. Com isso conseguimos propor a atividade com facilidade e interesse pela turma.

A primeira etapa consistiu em uma aula sobre a ferramenta apropriada para a criação de podcast's, chamado Audacity (figura 1). Este software é gratuito, de fácil manuseio e permite 
utilizar diversos recursos de configuração e modulação de voz, assim como sons ambientais ou fictícios e músicas de fundo que fornecem um apelo instigante por meio de gracejos que prendem a atenção de quem as escuta. Em seguida passamos para orientações quanto à escolha do tema abordado, o planejamento narrativo, a delimitação de objetivos e a estrutura didática. Após esta etapa, abrimos uma tarefa na plataforma Moodle para o envio do material, e um fórum de discussão para que a turma pudesse trocar ideias técnicas em relação ao programa, saber os temas escolhidos por cada um para evitar excessivas repetições temáticas.

Figura 1. Interface do programa Audacity em processo de edição de áudio.

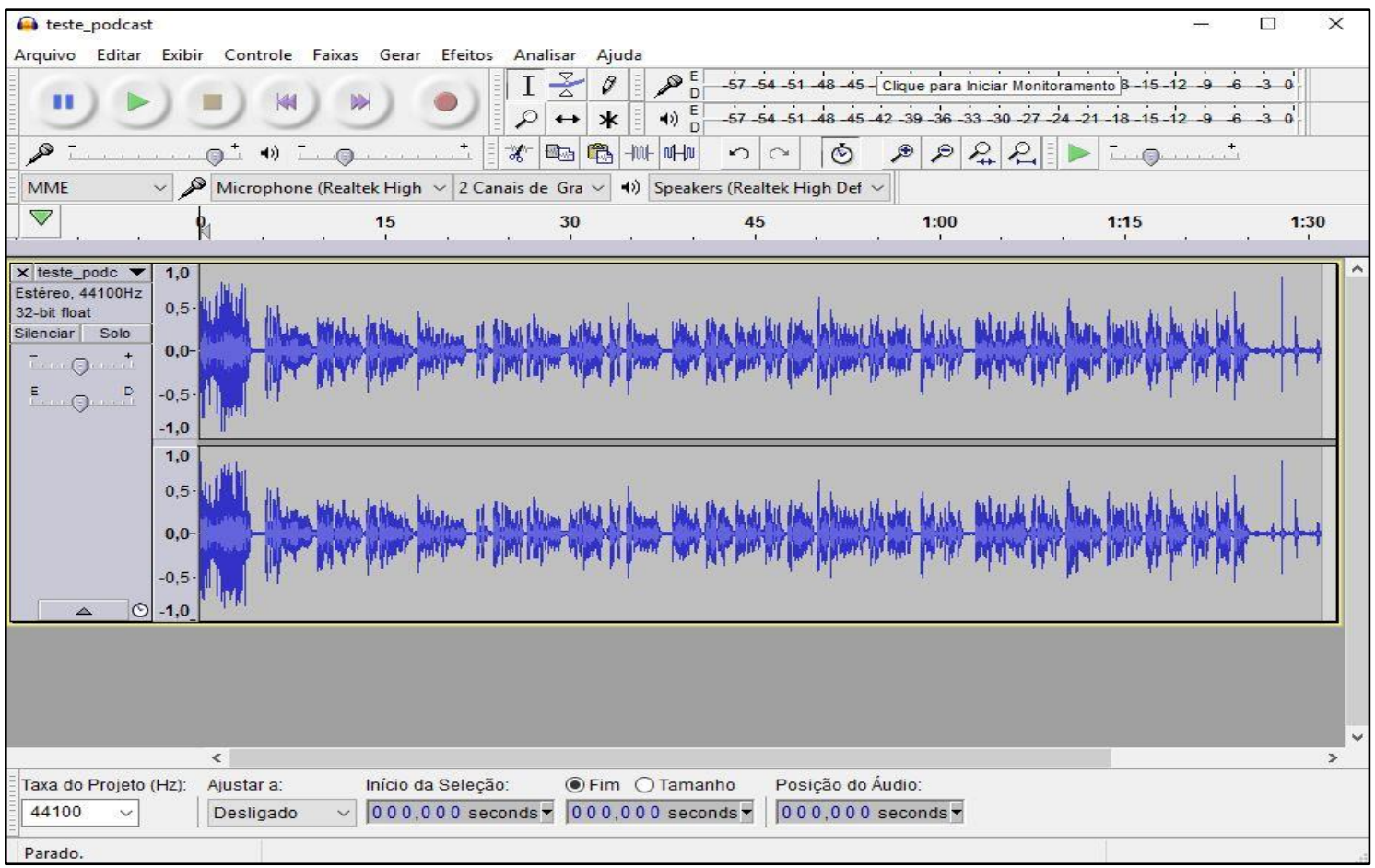

Fonte: do autor (2018).

Após o envio dos áudios, aproveitamos a aula para escutarmos juntos as gravações e discutirmos como foi o processo de criação, suas dificuldades, as formas utilizadas para superálas, bem como os conteúdos mais complexos de serem explicados principalmente por serem normalmente ensinados com o auxílio das imagens.

Por fim, colocamos os áudios no site CartoCurioso: O site da Cartografia Escolar (disponível em: <https://tuanytel.wixsite.com/cartografiaescolar〉) para que todos tivessem acesso, inclusive para utilizarem como ferramenta pedagógica em aula quando conveniente, como ferramenta na promoção da crítica construtiva, de acesso aos conteúdos e seus conceitos 
específicos, juntamente com a possibilidade de entretenimento e também para a diminuição da timidez.

Para acessar basta abrir o link, basta clicar em $\rightarrow$ Materiais de Apoio $\rightarrow$ CartoCast's.

Figura 2. CartoCast's disponíveis no site.

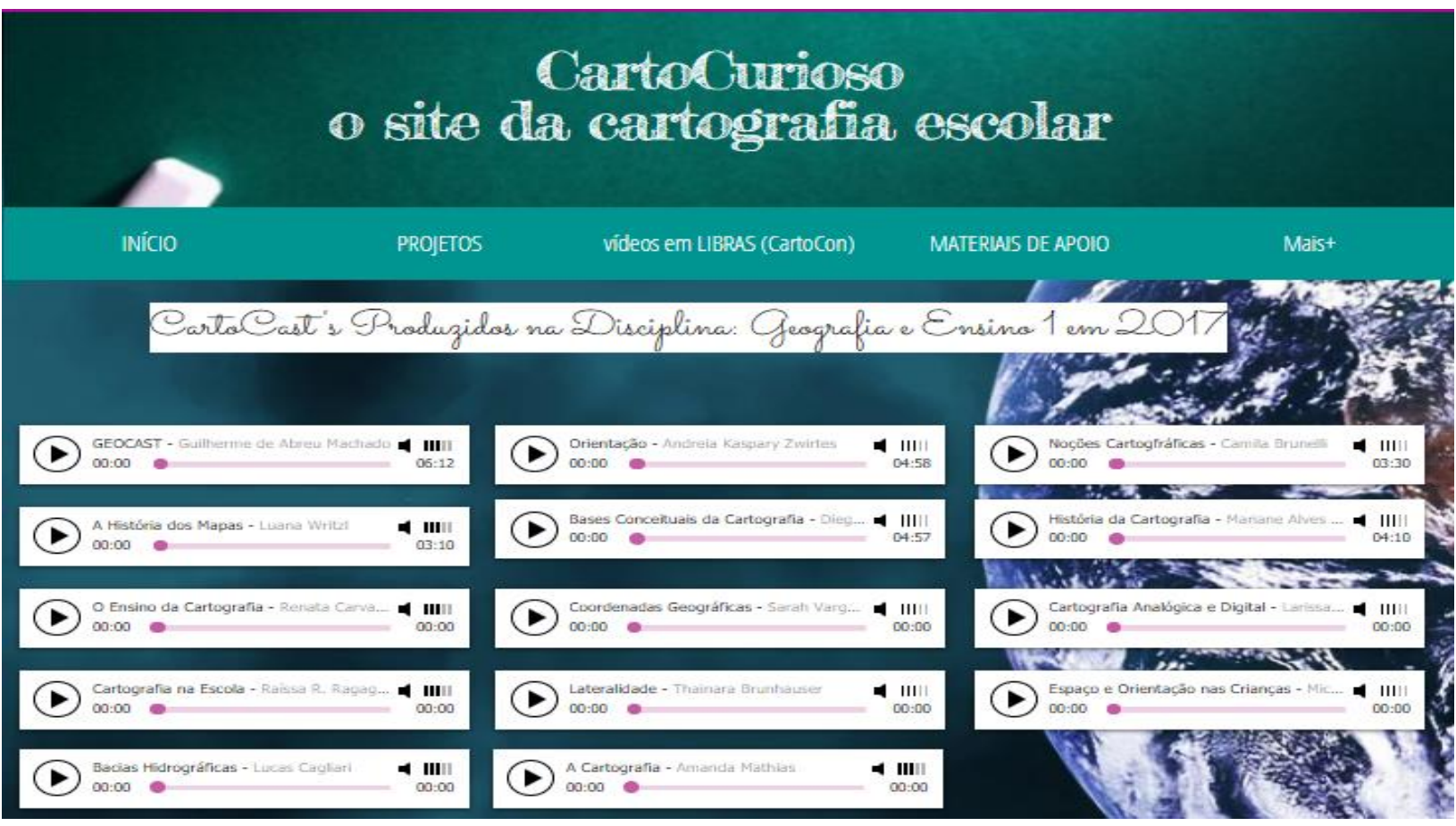

Fonte: do autor (2018).

\section{RESULTADOS E DISCUSSÕES}

Ao escutarmos os áudios, percebemos o empenho que cada um teve em propor o tema, construir a narrativa e editar sons complementares. Durante a discussão, grande parte dos alunos avaliou positivamente a utilização dos CartoCast's, e viram o processo criativo envolvido como uma momento de divertimento, embora tenham relatado que foram necessárias diversas tentativas de gravação dos áudios, pois como previsto os vícios de linguagem e o tempo ocioso que ocorre durante a reflexão promovida pela insegurança ao falar estiveram fortemente presentes. Mas ainda assim foi uma ótima oportunidade de se perceber e realizar uma autocrítica construtiva, principalmente com a superação da timidez. No entanto, a parte mais complexa, segundo seus relatos, foi a de explicar conteúdos sem o uso de imagens, pois para eles seria difícil separar o caráter visual da cartografia. Esse foi um dos anseios ao propormos os CartoCast's: conseguir transmitir os conteúdos de uma forma mais independente de outros recursos. 
Os CartoCas’t construídos tiveram predominância dos seguintes temas: a história dos mapas, conceitos cartográficos, o ensino de Cartografia e seu processo de alfabetização, delimitação de bacias hidrográficas, lateralidade, orientação e suas ferramentas, coordenadas geográficas, Cartografia Analógica e Digital. As escolhas temáticas estiveram relacionadas com a melhor capacidade de compreensão oral sem a necessidad de uso de imagens como exemplificação.

Ao final foi sugerido que o uso de CartoCast's ocorresse também na disciplina de Cartografia I, entretanto, com temaS voltados ao rigor cartográfico como uma forma de colaboração entre os integrantes das próximas turmas, que poderiam discutir e apresentar seus entendimentos sobre os conteúdos cartográficos para um público adulto e também futuros professores de Geografia em seu processo de formação profissional, assim como as outras disciplinas do curso de Geografia que poderiam se beneficiar do recurso.

Observando os resultados obtidos, e a impressão que os acadêmicos tiveram em relação à importância didática mostrou que o uso do software como ferramenta pra análise vocal e didática foi profundamente coerente com os objetivos propostos. Assim como enviar uma mensagem de áudio por uma rede social, como o WhatsApp, o locutor tem a possibilidade de escutar-se como forma de tentar perceber como o destinatário da mensagem pode interpretar aquilo que foi falado, desde o tom de voz utilizado até o uso de termos mais agressivos ou mais brandos, apropriados ao tipo de informação. A mesma preocupação ocorreu na construção dos CartoCast's, que forma elaborados de forma organizada e sistemática por meios de narrativas interessantes e com estruturas que contextualizassem com relações de proximidade como os sujeitos poderiam fazer uso de seus produtos, como forma de aprender mais sobre a Cartografia e o espaço geográfico.

Outras ferramentas podem ser úteis ao processo de evolução docente, bastando o empenho e o interesse das disciplinas dos cursos de graduação em formar profissionais atentos aos aspectos e ferramentas modernas no ensino e aprendizagem escolar. E a Geografia, enquanto ciência que estimula o pensamento e a crítica consciente, tem muito a beneficiar-se dessas propostas modernizadoras do ensino, sem abrir mão, obviamente, da presença do professor em sala de aula. Com isso uma boa didática tende a valorizar a presença do professor, e ao disponibilizar materiais de uso doméstico, além da sala de aula, faz do professor um agente transformador e presente constantemente na vida e no crescimento intelectual de seus alunos. 
Certamente o uso de Podcast's com a finalidade de ensinar pode ser utilizado por outras áreas do ensino de Geografia que busquem o constante aperfeiçoamento de ideais e transmissão oral de conhecimentos que facilitem o aprendizado de alunos em qualquer etapa escolar ou acadêmica. Com isso, finalizamos este artigo sugerindo o uso das tecnologias como forma de aprendizado profissional, como recursos audiovisuais e como a criação de vídeos ou a gravação de aulas expositivas com a mesma finalidade. É possível também o aperfeiçoamento de transmissão de informações em Língua Brasileira de Sinais (LIBRAS), utilizando os mesmos recursos, para que o futuro professor possa perceber-se e conseguir evoluir didaticamente em sua exposição de conteúdos vendo como os alunos o verão ou como as pessoas o percebem ao expor uma ideia dentro ou fora da escola.

\section{REFERÊNCIAS}

ALMEIDA, Rosângela D.; PASSINI, Elza Yasuko. O espaço geográfico: ensino e representação. $12^{\circ}$ ed. São Paulo: Contexto, 2002.

BENTO, Izabella P. Ensinar e Aprender Geografia: pautas contemporâneas em debate. Revista Brasileira de Educação Geográfica, Campinas, v. 4, n. 7, p. 143-157, jan./jun., 2014.

BRASIL. Ministério da Educação e do Desporto. Secretaria de Educação Fundamental. Parâmetros Curriculares Nacionais: Geografia. Brasília: MEC/SEF, 1998, p.33.

Ministério de Educação e do Desporto. Secretaria de Educação Fundamental. Parâmetros Curriculares Nacionais: terceiro e quarto ciclos do Ensino Fundamental: língua portuguesa, v. 2. Brasília: MEC/SEF, 1998.

CALLAI, H. C. O município: uma abordagem geográfica nos primeiros anos da formação básica. In: CAVALCANTI, L. de S. Temas da Geografia na escola básica. Campinas, SP: Papirus, 2013.

CASTROGIOVANNI, A. C. GOULART, Lígia Beatriz. A questão do livro didático em geografia: elementos para uma análise. In: CATROGIOVANNI, A. C. Geografia em Sala de Aula: práticas e reflexões. 2 ed. Porto Alegre: UFRGS, 1998.p. 129-132.

CASTILHO, A. T. Seria a língua falada mais pobre que a língua escrita? Impulso (Piracicaba), Piracicaba SP, v. 12, n. 27, p. 59-72, 2000.

DOLZ, J.; SCHNEUWLY, B.; DE PIETRO, J-F. A exposição oral. In: SCHNEUWLY, B., DOLZ, J. (Org.). Gêneros orais e escritos na escola. Campinas/SP: Mercado de Letras, 2004, p. 41-70.

FARIAS, Isabel Maria Sabino de. Didática e docência: aprendendo a profissão. Fortaleza: Liber, 2008. 
FREITAS, Felipe S; ABREU, Gustavo C. Uma Análise do Currículo local de Moçambique e da proposta do altas escolar da cidade de Maputo como formação continuada do professor e do aluno. In: Colóquio de Cartografia para Crianças e Escolares. Goiânia: UFG, 2016, 813 p.

ICA. International Cartographic Association. Hungria: Budapeste, 1989. Disponível em: <http://cartography.tuwien.ac.at/cartoheritage/>. Acesso em: 07/11/2018.

KENSKI, Vani Moreira. Educação e tecnologias: o novo ritmo da informação. Campinas: Papirus, 2010.

LACOSTE, Yves. A geografia, isso serve, em primeiro lugar, para fazer a guerra. Campinas: Papirus, 1997.

LIBÂNEO, José Carlos. Didática. São Paulo: Cortez, 1994.

MARCUSCHI, L. A. Da fala para a escrita: atividades de retextualização. 2. ed. São Paulo: Cortez, 2001. ; DIONÍSIO, A. P. Fala e escrita. Belo Horizonte: Autêntica, 2007.

MORAES, Antônio C. R. Geografia e Ideologia no $1^{\circ}$ Grau. In: BARRETO, Elba S. Os currículos do ensino fundamental para as escolas brasileiras. Formação de Professores, Campinas: Autores Associados, 1998.

PASSINI, E. Y. A alfabetização cartográfica e a aprendizagem de Geografia. São Paulo: Cortez, 2012.

Contexto, 2007.

Prática de ensino em Geografia e estágio supervisionado. São Paulo:

PONTUSCHKA, Nídia N.; PAGANELLI, Tomoko I.; CACETE, Núria H. Para ensinar e aprender Geografia. São Paulo: Cortez, 2009.

RICHTER, D.; BUENO, M. A. As potencialidades da Cartografia escolar: a contribuição dos mapas mentais e atlas escolares no ensino de Geografia. Anekumene, v.6, p.9-19, 2013.

SIMIELLI, Maria Elena R. O mapa como meio de comunicação: implicações no ensino de Geografia no $1^{\circ}$ grau. São Paulo, 1986. Tese (Doutorado)- FFLCH, Universidade de São Paulo.

SCHNEUWLY, J. Palavra e ficcionalização: um caminho para o ensino da linguagem oral. In: DOLZ, J; SCHNEUWLY, B. (Org.). Gêneros orais e escritos na escola. Campinas/SP: Mercado de Letras, 2004a, p.109-124.

STRAFORINI, Rafael. Ensinar Geografia: o desafio da totalidade-mundo nas séries iniciais. São Paulo: Annablume, 2004.

VESENTINI, J. W. (Org.) O Ensino da Geografia no Século XXI. Campinas: Papirus, 2004.

Data de Recebimento: 03/12/2018

Data de Aceite: 21/12/2018 